\title{
VARIATIONS OF IONOSPHERIC AND GEOMAGNETIC FIELD PARAMETERS DURING THE JUNE 18, 2013 BACHAT EARTHQUAKE
}

\author{
A.Yu. Belinskaya \\ Trofimuk Institute of Petroleum Geology and Geophysics SB RAS, \\ Novosibirsk, Russia, BelinskayaAY@ipgg.sbras.ru
}

\section{A.A. Kovalev}

Trofimuk Institute of Petroleum Geology and Geophysics SB RAS, Novosibirsk, Russia, KovalevAA@ipgg.sbras.ru

\author{
N.N. Semakov \\ Trofimuk Institute of Petroleum Geology and Geophysics SB RAS, \\ Novosibirsk, Russia, SemakovNN@ipgg.sbras.ru
}

\author{
S.I. Belinskaya \\ Irkutsk State Transport University, \\ Irkutsk, Russia,Sofiabel@mail.ru
}

\begin{abstract}
The paper presents the results of a study of variations in ionospheric parameters and local magnetic constant before, during, and after the Bachat earthquake, which occurred on June 18, 2013 at 23:02 UT (June 19, 2013 at 06:02 LT) with a magnitude 5.35.6 and epicenter coordinates $54.29^{\circ} \mathrm{N}, 86.17^{\circ}$ E. We have used data from IPGG SB RAS and TSU ionospheric stations and INTERMAGNET geomagnetic observatories. We have established that in the period preceding the earthquake there was a rather sharp increase in the magnetic moment, and in the subsequent period there was an equally sharp decrease in the magnetic moment. It is noted that the analysis of the daily average values of the local magnetic constant is the most promising for searching for geomagnetic precursors of earthquakes. We have found a low strong spo-
\end{abstract}

radic layer $\mathrm{E}_{\mathrm{s}}$ for two days before the event, the like of which was not observed for 15 days before and 15 days after the event. In addition, on the days preceding the shock, the background values of the F2-layer critical frequency were larger by more than $20 \%$ at the local pre-event hours. On the second day after the earthquake, there appeared a night-time region of low values (about $16 \%$ ), which persisted until the morning of the third day.

Keywords: earthquake, ionosphere, sporadic ionospheric layer, local magnetic constant.

\section{INTRODUCTION}

The Bachat earthquake with a magnitude 5.3-5.8 and epicenter coordinates of $54.29^{\circ} \mathrm{N}, 86.17^{\circ} \mathrm{E}$ occurred in the Bachat coal mine in the Kuzbass on June 18, 2013 at 23:02 UT (on June 19, 2013 at 06:02 LT). Intensity of the oscillations at the epicenter of the earthquake $I_{0}=7$. Kuzbass cities fell into the magnitude 5 zone; the earthquake was also felt outside the Kemerovo Region. Opinions on the genesis of the Bachat earthquake, reported in the literature, sometimes differ. Some authors treat it as self-evident that the earthquake was generated by anthropogenic activities [Emanov et al., 2014, 2016; Batugin, 2017; Adushkin, 2016; etc.], arguing that the hypocenter and most aftershocks were located directly under the coal strip mine, the natural geodynamic and hydrodynamic modes existing in the array changed under the influence of a complex of man-caused impacts, and the mountain range was regularly affected by industrial explosions with a total charge weight of hundreds of tons. Other authors, using numerical calculations, assume that the location of the hypocenter at a depth of several kilometers indicates a weak impact of mining operations and even contend that "... mining of coal in the Bachat mine could not cause the Bachat earthquake on June 18, 2013 because of a slight change in the strain-stress state near its vicinity, so the earthquake should not be considered as induced" [Lovchikov, Savchenko, 2016; etc.]. Comprehensive analysis of genesis of the Bachat earthquake [Kocharyan et al., 2019] has revealed that its main trigger was likely to be mining opera- tions that accelerated the occurrence of the earthquake, prepared by the natural evolution of the earth's crust. Thus, it can be considered as the largest natural and man-made seismic event ever recorded.

As is known, earthquakes can have an effect on geomagnetic variations. A number of studies have observed temporal variations in the value of the magnetic induction vector with different characteristic periods from a few minutes to hours, which may be associated with periods of preparation or relaxation of the crustal stress state [Guglielmi, Zotov, 2012; Chernogor, 2019]. The latter paper has identified trains of 400-900 s geomagnetic variations following an earthquake. The authors suggest that these variations might have been generated by electron density modulation under the action of seismic and acoustic-gravity waves. But variations with such periods may also be associated with the Sun's effect on Earth's magnetosphere. Mechanisms for generation of quasi-periodic geomagnetic variations driven by an earthquake might be provided by the generation of seismic waves in the lithosphere and infrasound and gravity waves in the atmosphere. The motion of the neutral component in the atmosphere provokes the motion of ionospheric plasma. Quasiperiodic variations of the electron density in the ionosphere lead to variations of ionospheric current density and, ultimately, to geomagnetic variations. Some papers delve into other intensity or angular components of geomagnetism [Spivak, Ryabova, 2019]. They usually analyze variations with a period of less than one day too. Nevertheless, a major 
drawback of these works lies in the fact that the value of the intensity components of geomagnetism analyzed actually depends not only on the change in the magnetic moment of the equivalent dipole, but also on the change in its orientation. These changes may have an opposite effect on the intensity component under study.

The distance from the epicenter to the IPGG SB RAS Geophysical Observatory of Solar-Terrestrial Physics (Novosibirsk) was about $200 \mathrm{~km}$. Thus, we could observe the state of the ionosphere over the epicenter, as the ionosonde provided information about the ionosphere up to the maximum electron density within a radius of about $250 \mathrm{~km}$ from the point of observation. Recent studies have revealed a relationship between geospheres, which also manifests itself in the lithosphere-atmosphere-ionosphere-magnetosphere coupling. Several days or hours before an earthquake, numerous abnormal changes occur in medium and electromagnetic field parameters [Liperovsky et al., 2008; Pulinets et al., 2015; Korsunova et al., 2013]. despite numerous studies in this field of research, there is, however, no generally accepted point of view allowing us to interpret ionospheric observations over seismically active regions, although there are several hypotheses. Ionospheric irregularities and their associated effects often reveal themselves during and after earthquakes; the irregularities are detected both in the neutral and ionized ionospheric components; the disturbances span large spatial scales. The effects that precede the earthquake were observed at all stations within the earthquake preparation zone, defined by the Dobrovolsky radius $R_{\mathrm{d}}=10^{0.43 M}$, where $R_{\mathrm{d}}$ is the preparation zone radius $(\mathrm{km}), M$ is the earthquake magnitude [Dobrovolsky et al., 1980].

\section{DATA ON \\ THE GEOMAGNETIC FIELD AND THE IONOSPHERE}

For the Bachat earthquake, the Dobrovolsky radius was a minimum of $190 \mathrm{~km}$, if not $312 \mathrm{~km}$ (different researchers give different estimates of its magnitude). Accordingly, we can safely say that the Geophysical Observatory of Solar-Terrestrial Physics falls into the preparation zone of this earthquake.

To eliminate the effects associated with sun exposure, we have analyzed daily average values of magnetic characteristics in nearby magnetic observatories. We use the local magnetic constant $\mathrm{G}$, which is purely an intensity magnetic field characteristic [Bauer, 1914]. From the observatories nearest to the center of the earthquake, we took the data freely available on the INTERMAGNET website [https://www.intermagnet. org] (see Table, where $r$ is the distance from the epicenter of the Bachat earthquake to a magnetic station).

For these observatories, we calculated the rate of change in the daily average value of the magnetic induction vector $(D F)$. In addition, the paper discusses the local magnetic constant $G$. It is related to the magnetic dipole moment $M$ by the relation $M=G R^{3}$, where $R$ is the distance from the dipole to an observation point. The $G$ value is calculated from the formula $G=\left(X^{2}+Y^{2}+0.25 Z^{2}\right)^{0.5}$ [Bauer, 1914]. Daily average values of the northward $(X)$, eastward $(Y)$, and vertical $(Z)$ components of the magnetic induction vector were computed from minute values taken from the INTERMAGNET website.

\begin{tabular}{|l|l|l|r|r|}
\hline \multirow{2}{*}{\multicolumn{1}{|c|}{ Station }} & \multirow{2}{*}{ Code } & \multicolumn{2}{|c|}{ Coordinates } & \multirow{2}{*}{${ }^{\circ}, \mathrm{km}$} \\
\cline { 3 - 5 } & & ${ }^{\circ}$ & ${ }^{\circ} \mathrm{E}$ & \\
\hline Novosibirsk & NVS & 54.85 & 83.23 & 201 \\
\hline Irkutsk & IRT & 52.27 & 104.45 & 1230 \\
\hline Almaty & AAA & 43.2 & 76.9 & 1407 \\
\hline
\end{tabular}

The paper presents 15-min data on ionospheric parameters obtained by the IPGG SB RAS Solar-Terrestrial Physics Observatory, NS355 station code, the distance to the epicenter is $201 \mathrm{~km}$, and by the TSU ionospheric station of CKP "Ionosphere Physics and Electromagnetic Ecology" (digital ionosonde Tomion), TK356 station code, the distance to the epicenter is $260.5 \mathrm{~km}$. We have analyzed critical frequencies and equivalent heights of the $\mathrm{E}, \mathrm{E}_{\mathrm{s}}, \mathrm{F} 1$, and F2 layers. For this event, we have also calculated moving median values for each hour and deviations of observed values from them (in percent).

\section{HELIOGEOPHYSICAL CONDITIONS DURING THE PERIOD OF INTEREST}

Figure 1, a presents solar activity characteristics for June 2013. We can see that five days before and five days after the Bachat earthquake there were no solar flares, increase in the solar wind, i.e. no significant solar influence on geospheres. According to world data [https://www.spaceweatherlive.com/ru/arhiv], geophysical conditions that time were also quiet (Figure 1, b).

\section{ANALYSIS OF RESULTS}

Figure 2 indicates that the spread of minute values of the magnetic induction vector $F$ on June 13-23, 2013 did not exceed $30 \mathrm{nT}$ and declination $D$ varied by no more than $0.4^{\circ}$ during the period. Thus, according to data from the nearest observatory Novosibirsk, the magnetic field on June 11-26, 2013 was fairly quiet.

The plot of values of the magnetic induction vector $F$ for the three stations (Figure 3) shows correlated changes in spaced stations. Notice that on June 18 the minimum diurnal variation of $F$ in Novosibirsk differed from that on the other days, whereas other stations further away from the epicenter did not observe this. It is clearly seen that on June 12-23 the value was perturbed, but the perturbations were observed not only in Novosibirsk, but also in Irkutsk and Almaty, so they should not be attributed to the Bachat earthquake.

Assuming that the distance from the central dipole to each of the observatories remains unchanged during the period considered, from a change in $G$ we can estimate a relative change in the magnetic moment (Figure 4).

It may be noted that the rate of change in the magnetic moment increased in the period preceding the earthquake and decreased in the subsequent period. Whether these changes are linked with the preparation of the seismic 


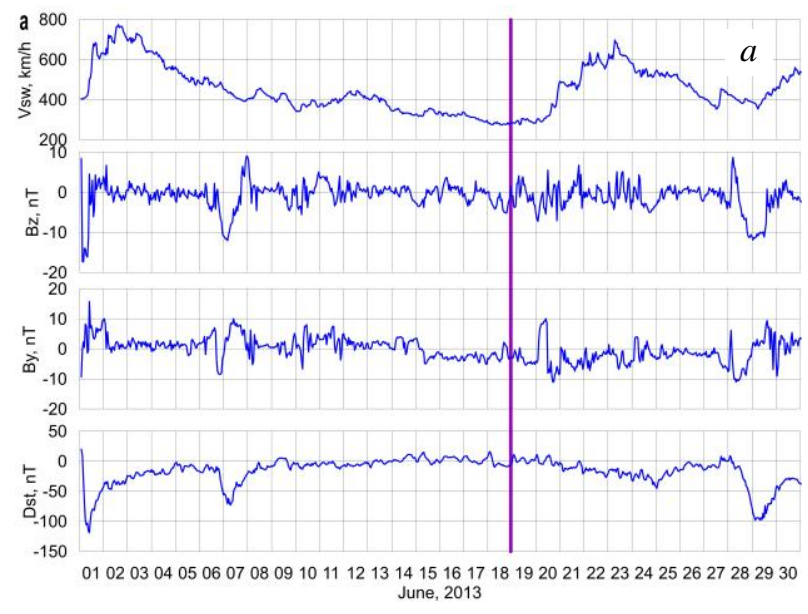

Kp index for June 2013

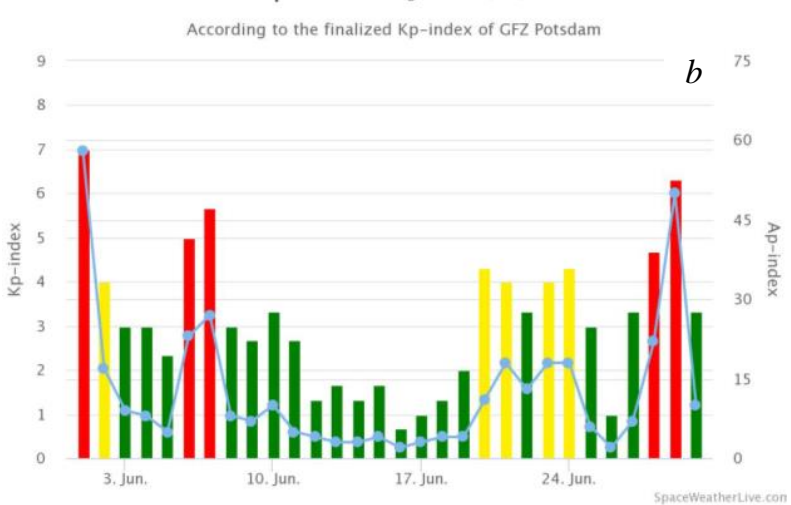

Figure 1. Solar activity in June 2013 The purple line is the day of the Bachat earthquake. From top to bottom on the panels: $a$ - the solar wind velocity, the direction of the interplanetary magnetic field $\left(B_{\mathrm{z}}\right.$ and $\left.B_{\mathrm{y}}\right)$, the $D s t$ index; $b-$ the geomagnetic indices $K_{\mathrm{p}}$ and $A_{\mathrm{p}}$ in June 2013 event and its release or not is a question to be addressed in the future.

Figure 5 illustrates variations in critical frequencies $f$ and equivalent heights $h$ for June 13-23, 2013 for Novosibirsk. It is clearly seen that two days before the Bachat earthquake and 24 hours after it ionospheric conditions were unusual. During that period, a low thick $\mathrm{E}_{\mathrm{s}}$ layer was observed which almost completely blanketed the F1 layer.

To clarify the situation in the ionosphere during the period, as mentioned above, we calculated the deviation of the ionospheric parameters from the 15-day moving average (Figure 6).

Two days before this earthquake, there was an excess over the background values of $f_{\mathrm{o}} \mathrm{F} 2$ by more than $20 \%$ during local pre-sunrise hours. On the second day after the earthquake, there was a region of decreased values (about $16 \%$ ) (Figure 6). Davidenko, Pulinets [2019] observed an increase in the F2-layer critical frequency (up to $24 \%$ ) from 22 to $7 \mathrm{LT}$, contrary to our observations 24 hours before the earthquake. The authors did not note decreased values after the earthquake. The differences might have been caused by the fact that the epicenter of the Bachat earthquake was closer to the point of ionospheric observations than epicenters of earthquakes to the vertical sounding stations in the aforementioned work.

The earthquake is most pronounced in characteristics of the $\mathrm{E}_{\mathrm{s}}$ layer (Figure 7). Two days before and on the day of the event there was an excess of the critical frequency values by $200 \%$ over the moving average. After the earthquake, $f_{\mathrm{o}} \mathrm{E}_{\mathrm{s}}$ decreased and the deviation was $60 \%$. Note that there were no such extreme deviations that month (Figure 7). Moreover, for two days before the earthquake the $\mathrm{E}_{\mathrm{s}}$-layer critical frequency

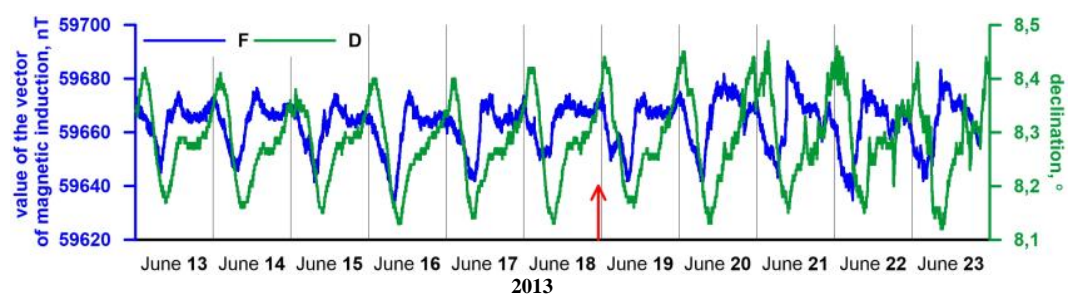

Figure 2. Value of the magnetic induction vector $F$ and declination $D$ at the observatory Novosibirsk for five days before and five days after the Bachat earthquake (red arrow)

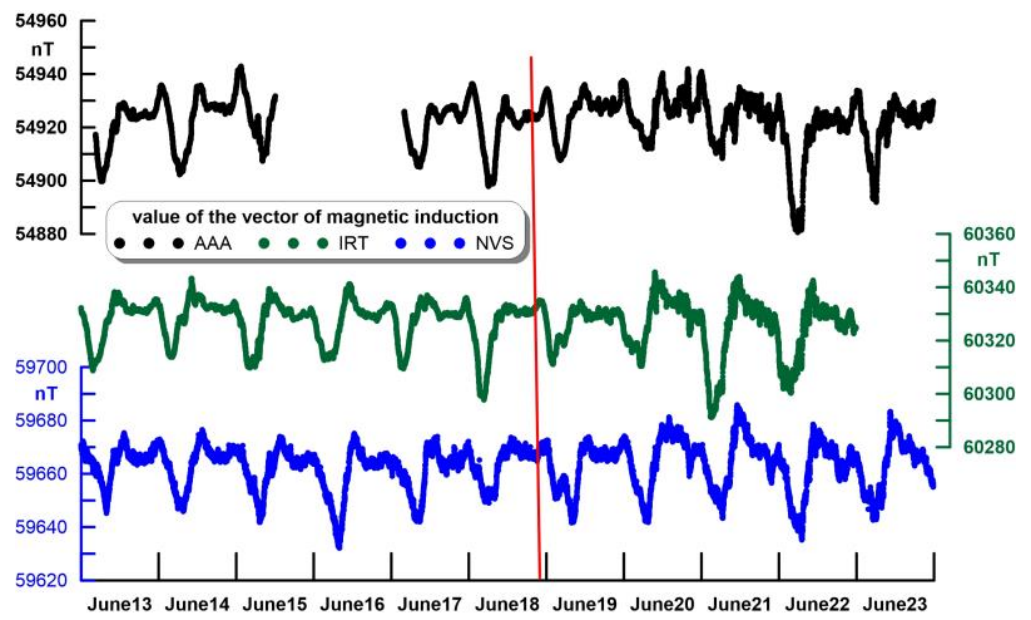

Figure 3. Value of the magnetic induction vector according to data from the geomagnetic observatories Novosibirsk, Irkutsk, and Almaty for five days before and five days after the Bachat earthquake (red line) 


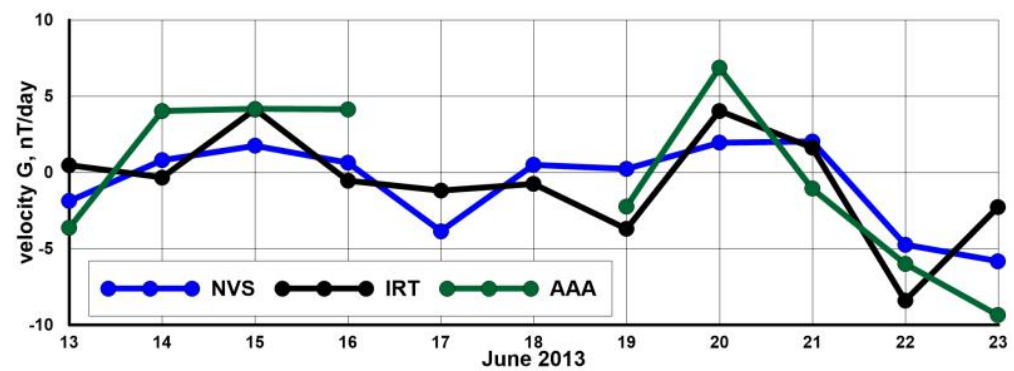

Figure 4. Rate of change in the local magnetic constant according to data from the geomagnetic observatories Novosibirsk, Irkutsk, and Almaty for five days before and five days after the Bachat earthquake

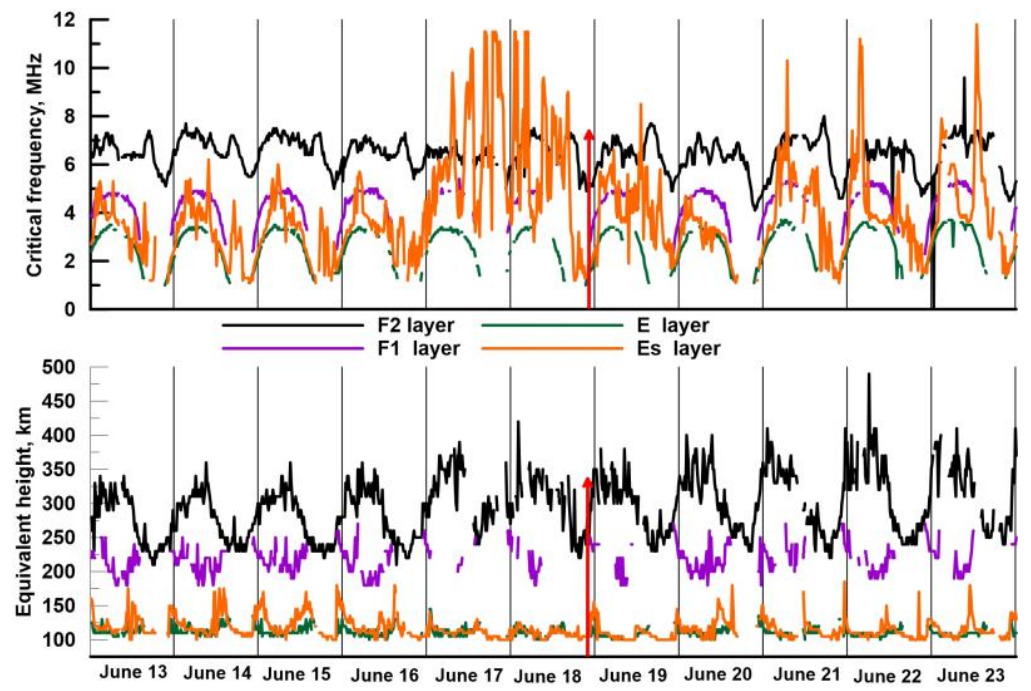

Figure 5. Variations in ionospheric parameters $f$ and $h$ for Novosibirsk five days before and five days after the Bachat earthquake (red arrow)

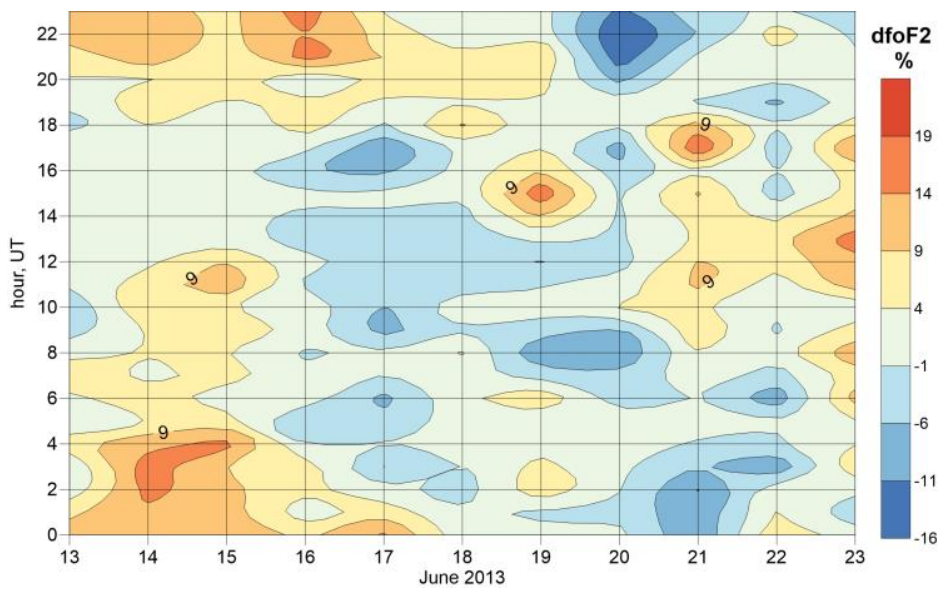

Figure 6. Diurnal deviation of the F2-layer critical frequency $d f_{\mathrm{o}} \mathrm{F} 2$ from background values as a percentage for five days before and five days after the Bachat earthquake

varied greatly (Figure 8). It is likely to be a manifestation of acoustic gravity waves generated in the surface layer of the atmosphere due to activation of seismogravity oscillations of the earth before earthquakes [Akhmedov, Kunitsin, 2004; Kunitsin et al., 2015].

To identify spatial characteristics of the behavior of the ionosphere during the period of interest, we have used vertical sounding data from Tomsk ionospheric station. Unfortunately, in June 2013 there were failures at this station; therefore we have data only for June 823. To compare the ionospheric parameters, we have used 15-min measurements of critical frequencies $f$ and equivalent heights $h$ of the ionospheric layers, addition- ally we have calculated differences in maximum ionization density in the $E_{s}$ layer for the two observation points at the same time (hour values). Notice that Tomsk ionospheric station is likely to be in the earthquake preparation zone, defined by the Dobrovolsky radius, if the upper estimates of the Bachat earthquake's magnitude are correct.

Figure 9 shows that disturbances in the $\mathrm{E}_{\mathrm{s}}$ layer also occurred over Tomsk for two days before the earthquake, but they had lower amplitude.

One of the main characteristic frequencies identified from a vertical sounding ionogram is the blanketing frequency $f_{\mathrm{b}}$ Es. It corresponds to the maximum 


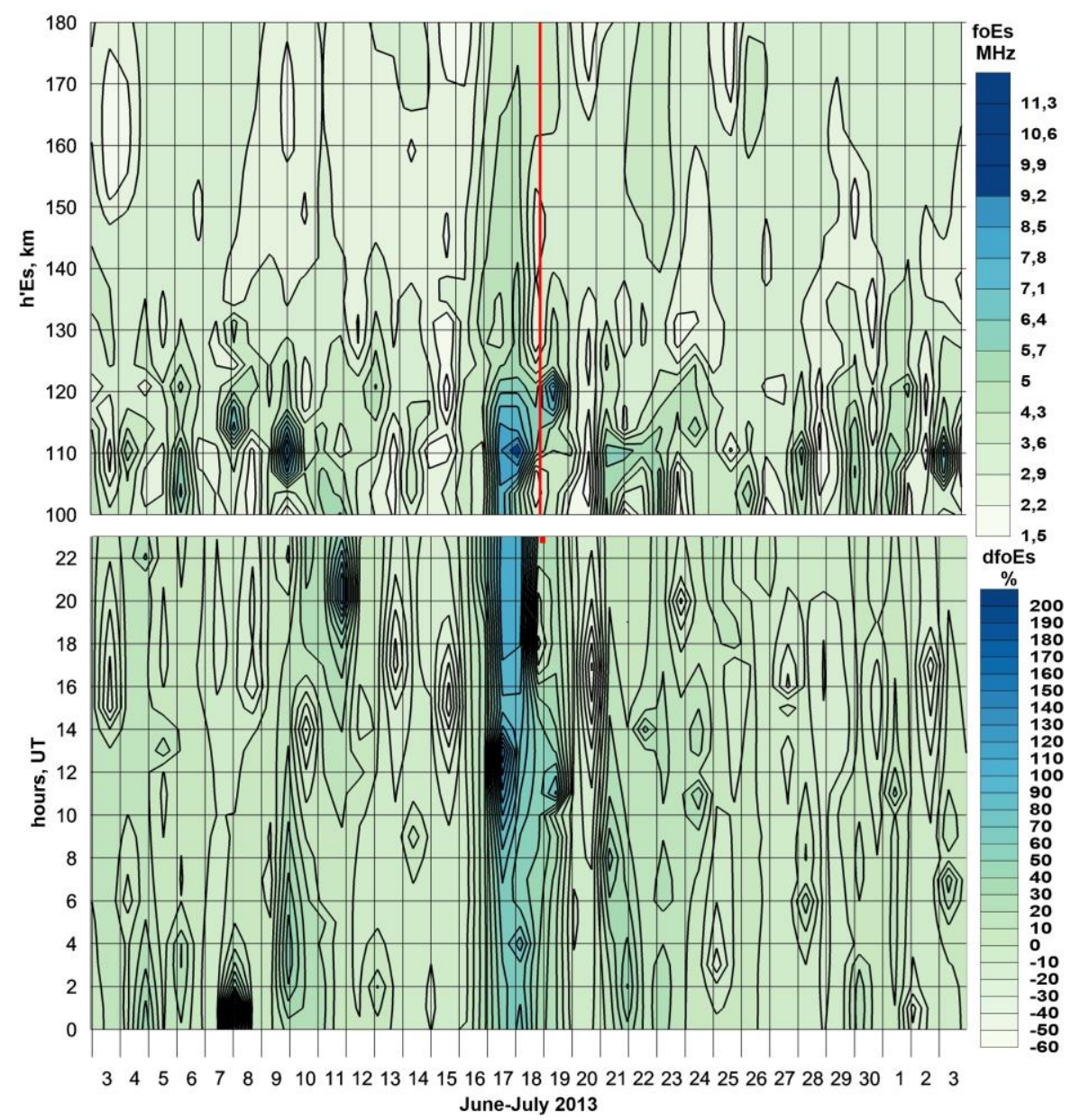

Figure 7. Values of the $\mathrm{E}_{\mathrm{s}}$-layer critical frequency as function of the day of observation and its equivalent height (top panel). The red line indicates the earthquake moment. Deviation of the $\mathrm{E}_{\mathrm{s}}$-layer critical frequency values from background values as function of the day and hour of observation as a percentage (bottom panel). The red dot denotes the earthquake moment

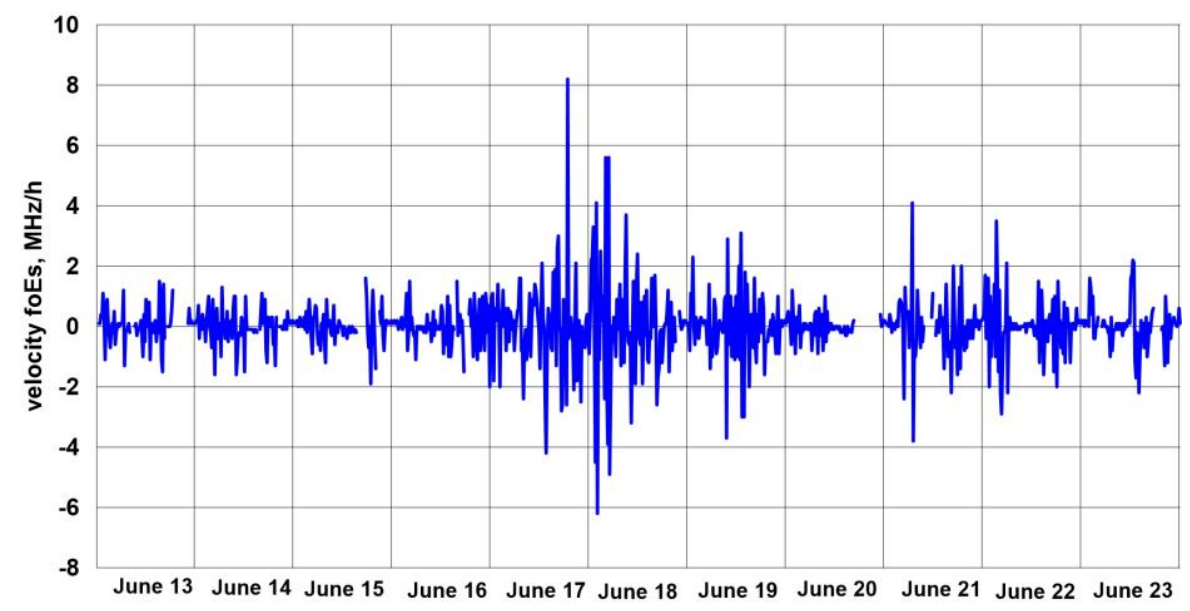

Figure 8. Rate of change of the $\mathrm{E}_{\mathrm{s}}$-layer critical frequency for five days before and five days after the earthquake in Novosibirsk

ionization density in the $\mathrm{E}_{\mathrm{s}}$ layer: $f_{\mathrm{b}} \mathrm{E}_{\mathrm{s}} \sim\left(N_{\max } \mathrm{E}_{\mathrm{s}}\right)^{1 / 2}$. Seismo-ionospheric effects in the $\mathrm{E}_{\mathrm{s}}$ layer may be caused by acoustic waves propagating from the Earth surface to ionospheric heights [Liperovsky et al., 1999]. Notice that two days before the event there was disruption of the diurnal variation in this value, clearly visible during the other days. Comparison between maximum ionization density values in the $\mathrm{E}_{\mathrm{s}}$ layer for spaced stations shows an interesting picture (Figure 10). In the period at two stations there were deviations (we calculated the deviation of Novosibirsk data from Tomsk data in percent) during all the days, but for two days before the main shock, we can see that over Novosibirsk the ionization density was much higher, whereas during the shock as such the values obtained at Tomsk increased sharply. The differences in the behavior of the sporadic layer between these two stations might be explained by different distances to the epicenter of the earthquake. 


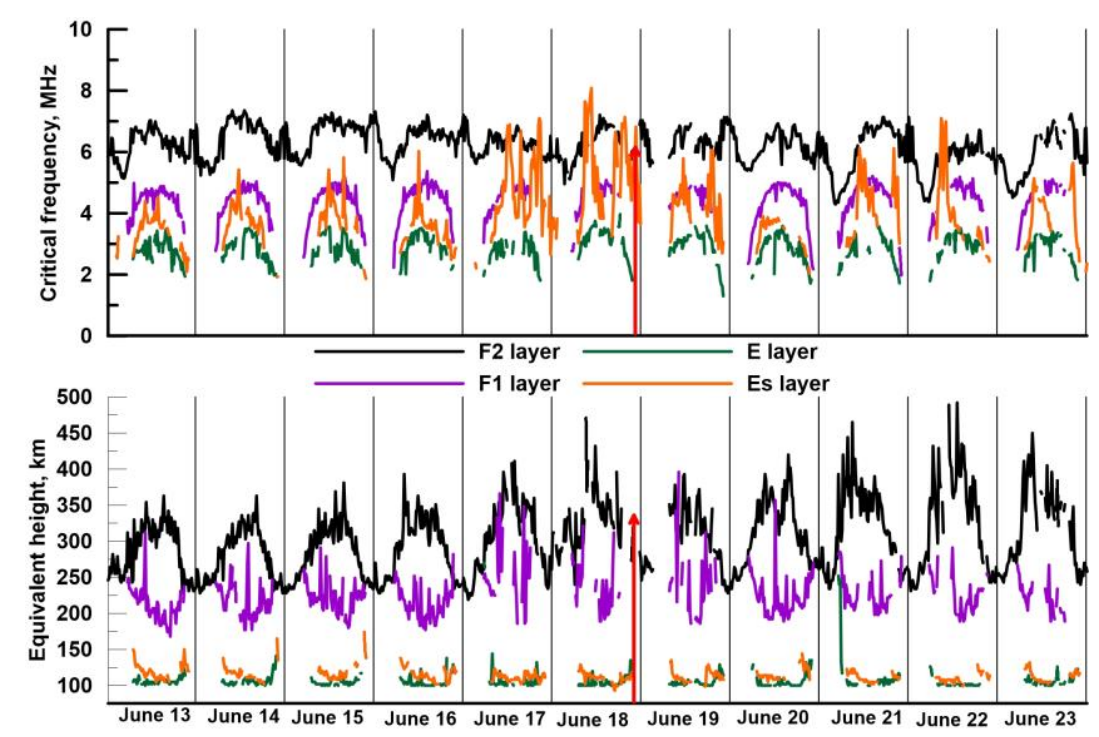

Figure 9. f- and h-plots of ionospheric parameters for Tomsk five days before and five days after the Bachat earthquake (red arrow)

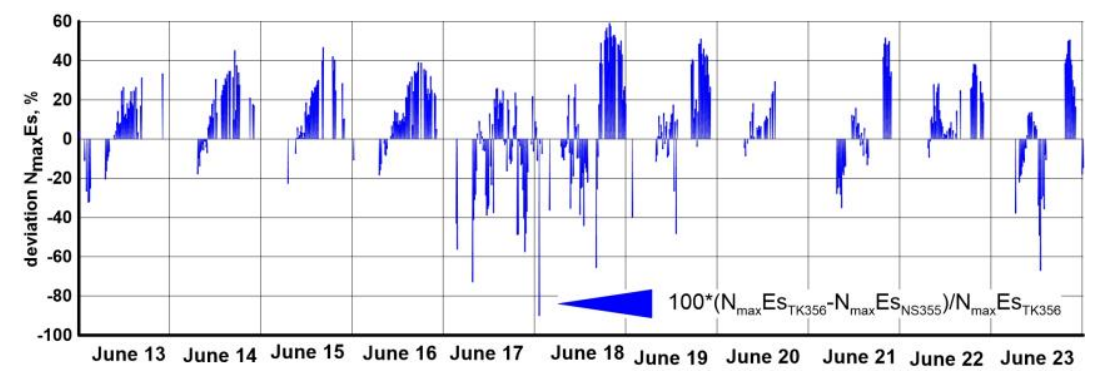

Figure 10. Differences between maximum ionization density values in the $E_{\mathrm{s}}$ layer over Tomsk and Novosibirsk in June 2013

\section{CONCLUSION}

The detailed analysis of the behavior of ionospheric and geomagnetic parameters before, during, and after the Bachat earthquake has shown the following:

- two days before the main shock in the lower ionosphere there were significant changes (higher ionization density in sporadic layers, their considerable hourto-hour variability, and low height of formation of these structures), these disturbances being less pronounced at a greater distance away from the epicenter;

- two days before the shock the background F2layer critical frequency increased during local presunrise hours, whereas on the second day after the earthquake this parameter decreased;

- we did not find significant variations in the geomagnetic field in the earthquake preparation zone.

To sum up, we may say that the most promising for searching for intensity geomagnetic precursors of earthquakes, in our opinion, is the analysis of the daily average local magnetic constant.

We express our gratitude to the team of Tomsk ionospheric station, as well as to teams of the magnetic observatories Irkutsk and Almaty for providing the data.

The work was financially supported by the Ministry of Science and Higher Education of the Russian Federation (project No. 0331-2019-0013).

\section{REFERENCES}

Adushkin V.V. Tectonic earthquakes of anthropogenic origin. Izvestiya, Physics of the Solid Earth. 2016, vol. 52, pp. 173-194. DOI: 10.1134/S1069351316020014.

Akhmedov R.R., Kunitsyn V.E. Simulation of the ionospheric disturbances caused by earthquakes and explosions. Geomagnetism and Aeronomy, 2004, vol. 44, no. 1, pp. 95-101.

Batugin A.S. To the analysis of tectonophysical conditions of earthquakes of anthropogenic origin. Issledovaniya po geoinformatike: trudy Geofizicheskogo tsentra RAN [Geoinformatics Research Papers: Proc. the Geophysical Center RAS]. 2017, vol. 5, no. 2, pp. 102-107. DOI: 10.2205/2017BS045. (In Russian).

Bauer L.A. The local magnetic constant and its variations. Terrestrial Magnetism and Atmospheric Electricity. 1914, vol. 19, no. 3, pp.113-125.

Chernogor L.F. Geomagnetic disturbances accompanying the Great Japanese Earthquake of March 11, 2011. Geomagnetism and Aeronomy. 2019, vol. 59, no. 1, pp. 62-75. DOI: 10.1134/S0016793219010043.

Guglielmi A.V., Zotov O.D. Magnetic perturbations before the strong earthquakes. Izv., Phys. Solid Earth. 2012, vol. 48, pp. 171-173. DOI: 10.1134/S1069351312010065.

Davidenko D.V., Pulinets S.A. Deterministic variability of the ionosphere on the eve of strong $(M \geq 6)$ earthquakes in the regions of Greece and Italy according to long-term measurements data. Geomagnetism and Aeronomy. 2019, vol. 59, no. 4, pp. 493-508.

Dobrovolsky I.P., Zubkov S.I., Myachkin V.I. Estimation of the size of the zone of manifestation of earthquake precur- 
sors. Modelirovanie predvestnikov zemletryasenii [Modeling of earthquake precursors], Moscow, Nauka Publ., 1980, pp. 7 24. (In Russian).

Emanov A.F., Emanov A.A., Fateev A.V., Leskova E.V., Shevkunova E.V., Podkorytova V.G. Technogenic seismicity of Kuzbass sections (Bachat earthquake on June 18, 2013). Fiziko-tekhnicheskie problemy razrabotki poleznykh iskopaemykh [Physical and Technical Problems of Mineral Development]. 2014, no. 2, pp. 41-46. DOI: 10.21455/VIS2016.4-3. (In Russian).

Emanov A.F., Emanov A.A., Fateev A.V., Leskova E.V. The technogenic Bachat earthquake of June 18, 2013 ( $M L=6.1)$ in the Kuznetsk Basin - the world's strongest in the extraction of solid minerals. Seismic Instruments. 2017, vol. 53, pp. 333-355. DOI: 10.3103/S0747923917040041.

Korsunova L.P., Khegai V.V., Mikhailov Yu.M., Smirnov S.E. Regularities in the manifestation of earthquake precursors in the ionosphere and near-surface atmospheric electric fields in Kamchatka. Geomagnetism and Aeronomy. 2013, vol. 53, no. 2, pp. 227-233. DOI: $10.1134 /$ S0016793213020084.

Kocharyan G.G., Kishkina S.B., Budkov A.M., Ivanchenko G.N. On the genesis of the 2013 Bachat earthquake. Geodinamika $i$ tektonofizika [Geodynamics \& Tectonophysics]. 2019, vol. 10, no. 3, pp.741-759. DOI: 10.5800/GT-2019-10 3-0439. (In Russian).

Kunitsyn V.E., Krysanov B.Yu., Vorontsov A.M. Acousticgravity waves in the Earth's atmosphere generated by surface sources. Moscow University Physics Bull. 2015, vol. 15, no. 6, pp. 541-548.

Liperovsky V.A., Senchenkov S.A., Liperovskaya E.V., Mayster K.-V., Rubtsov L.N., Alimov O.A. Studying disturbances in $f_{\mathrm{b}} \mathrm{E}_{\mathrm{s}}$ dynamics of the night mid-latitude $\mathrm{E}_{\mathrm{s}}$ layer from minute measurements. Geomagnetizm i aeronomiya [Geomagnetism and Aeronomy]. 1999, vol. 39, no. 1, pp. 131-134. (In Russian).
Liperovsky V.A., Pokhotelov O.A., Meyster K.-V., Liperovskaya E.V. Physical models of coupling in the lithosphereatmosphere-ionosphere system before earthquakes. Geomagnetism and Aeronomy. 2008, vol. 48, no. 6, pp.795-806. DOI: $10.1134 /$ S0016793208060133.

Lovchikov A.V., Savchenko S.N. On the technogenic nature of the Bachatsky earthquake 06.18.2013. Trudy Chetvertoi tektonofizicheskoi konferentsii IFZ RAN "Tektonofizika i aktual'nye voprosy nauk o Zemle" [Proc. the Fourth Tectonophysical Conference "Tectonophysics and Topical Issues of Earth Sciences"]. Moscow, 2016, pp. 478-480. (In Russian).

Pulinets S.A., Uzunov D.P., Karelin A.V., Davidenko D.V. Physical bases of the generation of short-term earthquake precursors: A complex model of ionization-induced geophysical processes in the lithosphere-atmosphere-ionosphere-magnetosphere system. Geomagnetism and Aeronomy. 2015, vol. 55, no. 4, pp. 521-538. DOI: 10.1134/S0016793215040131.

Spivak A.A., Ryabova S.A. Geomagnetic variations during strong earthquakes. Izvestiya, Physics of the Solid Earth. 2019, vol. 55, no 6, pp. 811-820. DOI: 10.1134/S1069351319060077.

URL: https://www.intermagnet.org (accessed June 5, 2020).

URL: https://www.spaceweatherlive.com/ru/arhiv (accessed June 5, 2020).

How to cite this article

Belinskaya A.Yu., Kovalev A.A., Semakov N.N., Belinskaya S.I. Variations of ionospheric and geomagnetic field parameters during the June 18, 2013 Bachat earthquake Solar-Terrestrial Physics. 2021. Vol. 7. Iss. 1. P. 78-84. DOI: 10.12737/stp-71202110. 